\title{
Impact of Acute Kidney Injury on the Survival of Subjects Receiving Noninvasive Ventilation
}

\author{
César Cinesi Gómez ${ }^{1 *}$, Natalia Trigueros Ruiz² ${ }^{2}$ José Andrés Sánchez Nicolás ${ }^{3}$ and Manuel Piñero Zapata ${ }^{4}$ \\ ${ }^{1}$ Emergency Department, Hospital General Universitario Reina Sofía, Doctor of Medicine, Alcalá University, Spain \\ ${ }^{2}$ Emergency Department, Hospital Universitario Reina Sofía, Spain \\ ${ }^{3}$ Emergency Department, Hospital General Universitario Reina Sofía, Doctor of Medicine, San Antonio Catholic University (UCAM) \\ ${ }^{4}$ Faculty of Nursing, San Antonio Catholic University (UCAM), Spain
}

Submission: January 05, 2018; Published: February 07, 2018

*Corresponding author: César Cinesi Gómez, Emergency Department, Hospital General Universitario Reina Sofía Murcia, Av/Intendente Jorge Palacios no1, ZP: 30003, Murcia, Spain, Tel: 968356666; Email: cesarcinesi@gmail.com

\begin{abstract}
Abstact
Objective: the main objective was to determine the presence of acute kidney injury (AKI) and the 90-day survival of subjects with acute respiratory failure (ARF) receiving noninvasive ventilation (NIV) in the Emergency Department (ED).

Method: We performed a prospective observational study. AKI was defined as the growth of level of creatinin between the one made in the ED, which had to be 1.5 times higher than the "basal value" (within the previous 3 months). Subjects were contacted by telephone at hospital discharge and at 30, 60 and 90 days after the initiation of NIV.

Result: We analyzed 174 cases: 30(17.3\%) subjects with AKI and 144(82.7\%) subjects no-AKI. Fifty-three percent of the subjects (16 subjects) with AKI died versus twenty percent (30 subjects) with no-AKI (RR 3.276; CI 95\%: 1.74-6.16. P<.001). Cox regression analysis showed the following to be statistically significant: subjects with AKI (HR 2.808; CI95\%: 1.497-5.291. P=.001), mean blood pressure (HR 0.969; CI95\%: 0.926-0.994. P=.044) and age (HR 1.039; CI 95\%: 1.007-1.71. P=.015).

Conclusion: The presence of AKI is an independent factor of mortality in subjects with ARF requiring NIV in the ED.

Abbreviations: ARF: Acute Respiratory Failure; ED: Emergency Department; IMV: Invasive Mechanical Ventilation; NIV: Non Invasive Ventilation; COPD: Chronic Obstructive Pulmonary Disease; APE: Acute Pulmonary Edema; AKI: kidney Injury; AKIN: Acute Kidney Injury Network; IPAP: Inspiratory Positive Airway Pressure
\end{abstract}

\section{Introduction}

The management of acute respiratory failure (ARF) in the Emergency Department (ED) is evolving from classical invasive mechanical ventilation (IMV) with endotracheal intubation to the "more recent" noninvasive ventilation (NIV) [1]. From almost the beginning of the implementation of the latter technique EDs were considered as fundamental strategic areas since early initiation of NIV reduces patient mortality [2] Exacerbations of chronic obstructive pulmonary disease (COPD) and acute pulmonary edema (APE) are the two most frequent diseases in the ED [1]. Factors associated with failure of NIV and lower patient survival include a low level of consciousness, high respiratory rate, $\mathrm{pH}$ values less than 7.25 , high scores in severity scales(APACHE, SOFA) or hemodynamic instability [2,3-7]. On adding IMV to these prognostic, it is observable a worsening in the kidney function, which leads to a higher mortality [810]. The evaluation of renal function consolidates acute kidney injury (AKI) which is based on the RIFLE [11] and Acute Kidney Injury Network (AKIN) criteria [12]. These criteria present two fundamental points: the first is a dynamic study of renal function according to changes over time, and the second is a grading of AKI depending on the relative decline in renal function. Both scales adequately determine the prognosis of the patient [1417]. However, studies on factors associated with NIV do not evaluate in depth the relationship between the renal function and the survival of these subjects $[2-5,14]$. Therefore, the aim of the present study is to determine the survival of subjects receiving NIV and the presence of AKI in the ED.

Methods we performed a prospective observational study carried out in the ED of the Hospital General Universitario Reina Sofía of Murcia (Spain) which attends a population of 202,000 inhabitants, with 92,297 emergencies having been attended in 2014. The study began on November 10, 2012 and finished on June 28, 2014. Patient recruitment was dynamic and consecutively included all the subjects attended in the ED. The inclusion criteria for these subjects were: 
a. Aged above 18 years.

b. ARF defined by $\mathrm{pO}_{2} / \mathrm{FiO}_{2}<300$.

c. NIV during the ED visit.

d. A diagnosis in ED that were of APE or COPD exacerbation.

The diagnosis for APE was base on clinical's foundings made by the ED's physician with a chest radiography compatible with APE. The COPD exacerbation is defined as a worsening of the patient's respiratory symptoms that is beyond normal day-today variations in subjects with known COPD.

A patient with a serum creatinine value carried out in the last 3 months. The exclusion criteria were: requirement for a lifesaving or emergency intervention, the necessity IMV before beginning with NIV and subjects receiving hemodialysis. The study followed the prevailing laws and regulation and was approved by the Ethical Committee of Clinical Investigation of our hospital. All the participants of the study provided informed consent. Confidentiality of all personal data was managed according to the Spanish Organic Law 15/1999, of 13 December on the protection of personal data. The main objective of the study was to determine the mortality at 90 days after the initiation of NIV and the presence of AKI. We determined serum creatinine $(\mathrm{mg} / \mathrm{dl})$ levels at admission to the ED. To define the "basal value" we had to use the last measurement of serum creatinine made to the patient. This measurement had a deadline of three months. AKI was defined as the growth of level of creatinine between the one made in the ED, which had to be 1.5 times higher than the "basal value". The subjects that were discharged were telephoned at 30, 60 and 90 days after the initiation of NIV. The study included secondary objectives were the mortality rate during hospitalization, admission to the intensive care unit (ICU), mortality at 30 and 60 after the initiation of NIV and mortality according diagnosis(APE, COPD exacerbation). Mortality was also taken into account according to the AKIN criteria [13]. NIV was the administration of continuos positive airway pressure (CPAP) or Bilevel positive airway pressure (BiPAP) applied through a interface. All subjects were continuously monitored. The ventilators used for NIV were either BiPAP model ST or Trilogy 202 (Respironics; Murrysville, $\mathrm{PA})$. The initial ventilator

Settings are as follows:

I. BiPAP Mode: Inspiratory Positive Airway Pressure (IPAP) between $10-16 \mathrm{~cm} \mathrm{H}_{2} \mathrm{O}$ and an Expiratory Positive Airway Pressure (EPAP) of $4 \mathrm{~cm} \mathrm{H}_{2} \mathrm{O}$. After, the pressure (increasing the pressure support in $2 \mathrm{~cm} \mathrm{H}_{2} \mathrm{O}$ each time) was adjusted to achieve an expiratory mean tidal volume of at least $5 \mathrm{ml} / \mathrm{kg}$.

II. CPAP Mode: EPAP of $5 \mathrm{~cm} \mathrm{H}_{2} \mathrm{O}$, increasing the pressure to $10-15 \mathrm{~cm} \mathrm{H}_{2} \mathrm{O}$. The IBM SPSS Statistics $\mathrm{v}-21$ was used for the statistical analyses. Categorical variables were expressed as absolute values and percentages. Continuous values were expressed as mean, standard deviation and median. In addition, the type of distribution was determined using the KolmogorovSmirnov test. Differences between categorical variables were evaluated using the Chi square and continuous variables were analyzed with the Student's T test if the distribution was normal or the Mann-Whitney U test if otherwise. The relative risks were calculated with their 95\% confidence intervals (CI 95\%). To determine associations between the continuous variables and the different groups the ANOVA or Kruskall-Wallis test was used. To discriminate the confounding power of the variables, Cox regression analysis was used performing univariate analysis of the statistically significant variables (not only regarding AKI, but also the mortality) and including the subjects with AKI. KaplanMeier analysis was performed for survival analysis, and the curves were compared using the Log rank test. A p value $<0.05$ was considered significant.

Results

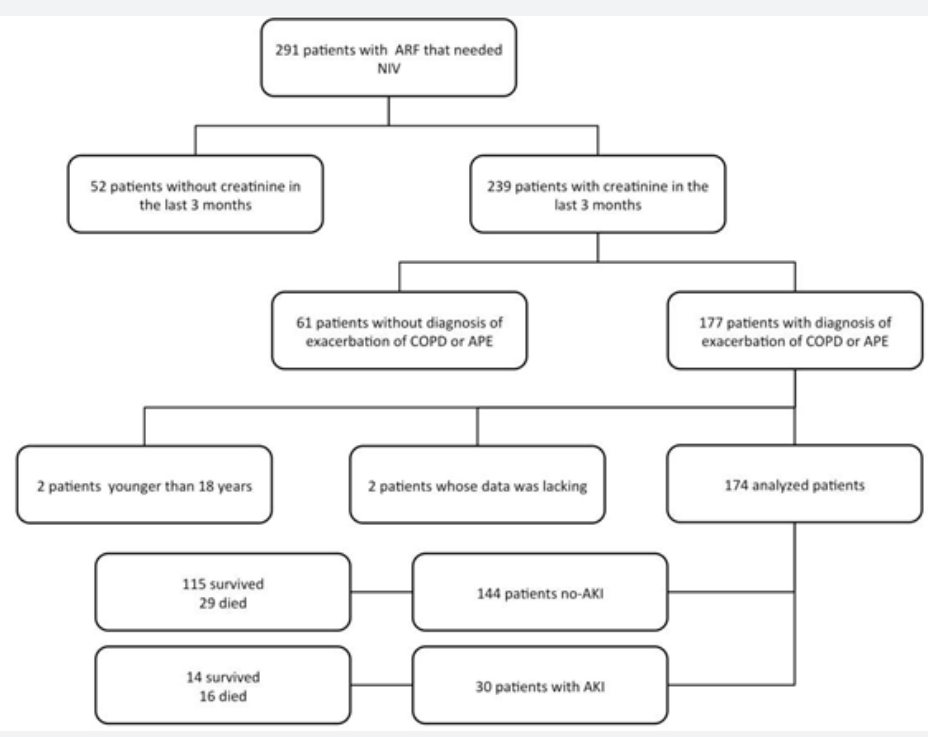

Figure 1 
ARF: Acute Respiratory Failure.

NIV: Noninvasive Ventilation.

COPD: Chronic Obstructive Pulmonary Disease.

APE: Acute Pulmonary Edema.

AKI: Acute Kidney Injury.

A total of 291 cases were included, 52(17.8\%) of which were excluded for lacking serum creatinine determinations in the previous 3 months, 61(20.9\%) presented a different diagnosis exacerbation of COPD or APE, in $2(0.68 \%)$ cases data were lacking and $2(0.68 \%)$ were less than 18 years of age. Thus, 174 cases $(59.7 \%$ of the subjects) were finally analyzed (Figure 1). One hundred forty-four subjects (82.7\%) didn't have Acute Kidney Injury (no-AKI), while 30 subjects (17.2\%) developed an Acute Kidney Injury (AKI). Table 1 shows the basal characteristics of the subjects comparing those with AKI with

Table 1: Main characteristics of patients with Acute Kidney Injury*. subjects with no-AKI. Of the 174 subjects studied, 45(25.9\%) died within 90 days of ED discharge. Among subjects with AKI the mortality at 90 days was $53.3 \%$ (16 subjects) compared to $20.1 \%$ (29 subjects) in those with no-AKI (RR 3.276; CI 95\%:1.74- 6.16.P<.001). The global in-hospital mortality was $14.3 \%$ (25 subjects), $30.0 \%$ with AKI vs $11.1 \%$ no-AKI (RR 2.554; CI 95\%:1.32-4.92.P=0,007). Tables 2 \& 3 show the data related to mortality. Urea, serum creatinine, creatinine clearance and previous serum creatinine values showed no statistically significant relationship with 90-day mortality, with P values of $.133, .269,0118$ and .527 , respectively. However, the difference in serum creatinine levels $(1.14 \pm 0.89$ vs. $0.28 \pm 0.51 \mathrm{mg} / \mathrm{dl} ; \mathrm{P}=.024)$ were found to be related to mortality at 90 days. Regarding the in-hospital mortality, a significative statiscal difference was found as regards the serum creatinine $(1.76 \pm 0.93$ vs. $1.37 \pm 0.68$ $\mathrm{mg} / \mathrm{dl} ; \mathrm{P}=0.014$ ) and the difference in serum creatinine levels $(0.57 \pm 0.91$ vs. $0.21 \pm 0.35 \mathrm{mg} / \mathrm{dl} ; \mathrm{P}=.039)$.

\begin{tabular}{|c|c|c|c|c|}
\hline & All units & No-AKI & AKI & p-value $\dagger$ \\
\hline & $(N=174)$ & $(N=144)$ & $(N=30)$ & \\
\hline Age (years) & $76,60 \pm 11,3(78,0)$ & $76,58 \pm 10,5(77,0)$ & $76,67 \pm 14,9(80,5)$ & 0,403 \\
\hline Sex (Males) - n (\%) & $93(53,4)$ & $80(55,6)$ & $13(43,3)$ & 0,237 \\
\hline Hypertension - n (\%) & $151(86,8)$ & $125(86,8)$ & $26(86,7)$ & 0,984 \\
\hline Diabetes mellitus - n (\%) & $84(48,3)$ & $71(49,3)$ & $13(43,3)$ & 0,552 \\
\hline Chronic Kidney Dissease - n (\%) & $35(20,1)$ & $34(23,6)$ & $1(3,3)$ & 0,013 \\
\hline Domiciliary oxygen therapy $-\mathrm{n}(\%)$ & $60(34,5)$ & $52(36,1)$ & $8(26,7)$ & 0,322 \\
\hline Domiciliary NIV $\neq-\mathrm{n}(\%)$ & $41(23,6)$ & $35(24,3)$ & $6(20,0)$ & 0,613 \\
\hline Body Mass Index (Kg/m2) - n (\%) & $30,32 \pm 7,4(29,01)$ & $30,51 \pm 6,8(29,35)$ & $29,28 \pm 10,9(27,00)$ & 0,383 \\
\hline Glasgow Score & $13,91 \pm 2,2(15,0)$ & $14,16 \pm 1,9(15,0)$ & $12,77 \pm 3,0(14,5)$ & 0,004 \\
\hline \multicolumn{5}{|l|}{ Blood Pressure (mm Hg) } \\
\hline Systolic & $142,35 \pm 34,0(138,0)$ & $143,95 \pm 34,9(138,0)$ & $134,62 \pm 28,5(130)$ & 0,183 \\
\hline Mean & $98,33 \pm 22,8(94,0)$ & $99,84 \pm 23,7(95,0)$ & $91,05 \pm 15,9(91,3)$ & 0,068 \\
\hline Heart Rate (bpm) & $94,67 \pm 23,9(93,0)$ & $95,36 \pm 24,8(94,0)$ & $91,34 \pm 21,4(90,0)$ & 0,732 \\
\hline $\mathrm{pO}_{2} / \mathrm{FiO}_{2} \S$ & $215,73 \pm 68,6(224,7)$ & $212,71 \pm 69,7(224,2)$ & $231,55 \pm 62,9(224,7)$ & 0,436 \\
\hline $\mathrm{pH}$ & $7,281 \pm 0,09(7,29)$ & $7,292 \pm 0,08(7,30)$ & $7,224 \pm 0,12(7,23)$ & 0,003 \\
\hline $\mathrm{pCO}_{2}(\mathrm{~mm} \mathrm{Hg})$ & $66,10 \pm 25,1(61,9)$ & $64,51 \pm 24,4(60,1)$ & $73,75 \pm 27,40(70,3)$ & 0,067 \\
\hline Patients with $\mathrm{CO}_{2}>45 \mathrm{mmHg}$ (Hypercapnia) - n (\%) & $115(66,1)$ & $91(63,2)$ & $24(80,0)$ & 0,077 \\
\hline Bicarbonate $(\mathrm{mmol} / \mathrm{L})$ & $25,79 \pm 5,8(25,2)$ & $26,18 \pm 5,8(25,2)$ & $23,93 \pm 5,6(23,8)$ & 0,065 \\
\hline Urea $(\mathrm{mg} / \mathrm{dl})$ & $64,25 \pm 38,4(55,0)$ & $59,94 \pm 35,8(53,5)$ & $84,93 \pm 45,3(76,5)$ & 0,002 \\
\hline Creatinine (md/dl) & $1,430 \pm 0,73(1,30)$ & $1,344 \pm 0,66(1,20)$ & $1,843 \pm 0,91(1,55)$ & $<0,002$ \\
\hline Creatinine clearance $(\mathrm{ml} / \mathrm{min})$ & $57,15 \pm 31,2(50,09)$ & $59,50 \pm 31,7(51,5)$ & $44,25 \pm 28,1(36,8)$ & 0,009 \\
\hline Previous Creatinine (mg/dl) ॥ & $1,17 \pm 0,56(1,10)$ & $1,22 \pm 0,58(1,10)$ & $0,91 \pm 0,32(0,88)$ & 0,007 \\
\hline Difference between creatinines (mg/dl) & $0,26 \pm 0,48(0,20)$ & $0,12 \pm 0,25(0,16)$ & $0,97 \pm 0,69(0,72)$ & $<0,001$ \\
\hline
\end{tabular}


International Journal of Pulmonary \& Respiratory Sciences

\begin{tabular}{|c|c|c|c|c|}
\hline Time between the relization of both Creatinines (days) & $22,84 \pm 13,98(15,0)$ & $22,12 \pm 13,50(15,0)$ & $26,87 \pm 16,17(15,0)$ & 0,264 \\
\hline SOFA & $3,75 \pm 1,39(4,0)$ & $3,62 \pm 1,37(3,5)$ & $4,33 \pm 1,41(5,0)$ & 0,178 \\
\hline proBNP (pg/ml) & $5.303 \pm 7.246(2.772)$ & $4.936 \pm 7.292(2.609)$ & $7.116 \pm 6.851(5.161)$ & 0,076 \\
\hline Procalcitonin (ng/dl) & $0,51 \pm 3,8(0,05)$ & $0,50 \pm 4,2(0,00)$ & $0,54 \pm 1,2(0,11)$ & 0,023 \\
\hline Lactic Acid (mmol/L) & $2,186 \pm 1,63(1,60)$ & $2,103 \pm 1,65(1,50)$ & $2,579 \pm 1,49(1,49)$ & 0,028 \\
\hline Diagnostic & & & & $15(50,0)(17,0)$ \\
\hline Acute Pulmonary Edema - n (\%) & $88(50,6)(100)$ & $73(50,7)(83,0)$ & 0,945 \\
\hline COPD Exacerbation - n (\%) & $86(49,4)(100)$ & $71(49,3)(82,6)$ & $15(50,0)(17,4)$ & 0,973 \\
\hline
\end{tabular}

* Continuous values are presented as mean \pm SD (median)

If In the lowest line the percentage amoung the group are shown.

$\dagger p$-value to contrast both groups.

$\ddagger$ Any type of domiciliary noninvasive ventilator

AKI: Acute Kidney Injury.

NIV: Noninvasive Ventilation.

$\S$ Inspiratory oxygen fraction.

COPD: Chronic Obstructive Pulmonary Dissease.

|| Creatinine obtained from analyses in the last three months.

SOFA: Sequential Organ Failure Assessment.

Table 2: Relationship between mortality, ICU admission and the presence of $\mathrm{AKI}^{*}$.

\begin{tabular}{|c|c|c|c|c|}
\hline Outcome & No-AKI & AKI & RR (IC 95\%) & p-value $\dagger$ \\
\hline & $(\mathrm{N}=144)$ & $(\mathrm{N}=30)$ & & \\
\hline \multicolumn{5}{|l|}{ End-Point } \\
\hline Death at day $90-\mathrm{n}(\%)$ & $29(20,1)$ & $16(53,3)$ & $3,276(1,74-6,16)$ & $<0,001$ \\
\hline \multicolumn{5}{|l|}{ Secundary outcomes } \\
\hline Death in-Hospital - n (\%) & $16(11,1)$ & $9(30,0)$ & $2,554(1,32-4,92)$ & 0,007 \\
\hline Death at Day $30-\mathrm{n}(\%)$ & $22(15,3)$ & $12(40,0)$ & $2,745(1,46-5,13)$ & 0,002 \\
\hline Death at Day $60-\mathrm{n}(\%)$ & $25(17,4)$ & $16(53,3)$ & $3,707(1,98-6,93)$ & $<0,001$ \\
\hline ICU Admission $\neq-\mathrm{n}(\%)$ & $12(8,3)$ & $2(6,7)$ & $0,816(0,21-3,07)$ & 0,760 \\
\hline \multicolumn{5}{|l|}{ Mortality according to Diagnosis§ } \\
\hline Acute Pulmonary Edema - n (\%) & $13 / 73(17,8)$ & $8 / 15(53,3)$ & $2,99(1,51-5,93)$ & 0,003 \\
\hline COPD|| Exacerbation - n (\%) & $16 / 71(22,5)$ & $8 / 15(53,3)$ & $2,952(1,20-7,24)$ & 0,016 \\
\hline
\end{tabular}

${ }^{*}$ AKI: Acute Kidney Injury.

$\dagger p$-value to contrast both groups.

$\ddagger$ ICU: Intensive Care Unit

$\S$ The number of event is shown/ total amount within the diagnosis.

|| COPD: Chronic Obstructive Pulmonary Diseases.

Table 3: Relationship between mortality and ICU admission in patients with AKIN*.

\begin{tabular}{|c|c|c|c|c|c|}
\hline Outcome & AKIN 0 & AKIN 1 & AKIN 2 & AKIN 3 & p-value $\dagger$ \\
\hline & $(\mathrm{N}=144)$ & $(\mathrm{N}=\mathbf{2 1})$ & $(\mathrm{N}=6)$ & $(\mathrm{N}=3)$ & \\
\hline \multicolumn{6}{|l|}{ End-Point } \\
\hline Death at Day 90 - n (\%) & $29(20,1)$ & $9(42,9)$ & $4(66,7)$ & $3(100)$ & $<0,001$ \\
\hline \multicolumn{6}{|l|}{ Secundary Outcomes } \\
\hline Death in-hospital - n (\%) & $16(11,1)$ & $5(23,8)$ & $2(33,3)$ & $2(66,7)$ & 0,011 \\
\hline Death at Day $30-\mathrm{n}(\%)$ & $22(15,3)$ & $6(28,6)$ & $3(50,0)$ & $3(100)$ & $<0,001$ \\
\hline Death at Day 60 - n (\%) & $25(17,4)$ & $9(42,9)$ & $4(66,7)$ & $3(100)$ & $<0,001$ \\
\hline ICU Admission $\neq-\mathrm{n}(\%)$ & $12(8,3)$ & $1(4,8)$ & $0(0,0)$ & $1(33,3)$ & 0,329 \\
\hline \multicolumn{6}{|l|}{ Mortality according to Diagnosis§ } \\
\hline Acute Pulmonary Edema - n (\%) & $13 / 73(17,8)$ & $3 / 9(33,3)$ & $4 / 5(80,0)$ & $1 / 1(100)$ & 0,003 \\
\hline COPD|| Exacerbation - n (\%) & $16 / 71(22,5)$ & $6 / 12(50,0)$ & $0 / 1(0)$ & $2 / 2(100)$ & 0,024 \\
\hline
\end{tabular}


With regard to the remaining variables studied, among the categorical variables none of them showed a significative statiscal relationship with 90-day and in-hospital mortality. To the contrary, of the variables the following were statistically significant: aged $(75.27 \pm 11.4$ vs $80.40 \pm 10.4$ years. $\mathrm{P}=.004)$, mean blood pressure $(100.7 \pm 22$. vs $91.3 \pm 21.4 \mathrm{mmHg}$. $\mathrm{P}=.010)$, pro BNP (4627.0 \pm 6299.5 vs $7244.1 \pm 9264.3 \mathrm{pg} / \mathrm{ml}$. $\mathrm{P}=.040$ ); procalcitonin $0.48 \pm 4.4 \mathrm{ng} / \mathrm{dl}$ vs $0.59 \pm 1.5 \mathrm{ng} / \mathrm{dl}$. $\mathrm{P}=.001$ ) and SOFA score $(3.5 \pm 1.1$ vs $4.6 \pm 1.7$. $\mathrm{P}=.023)$. No relationship was observed between the presence of AKI and the probability of admission to the intensive care unit (ICU), with ICU admission of $8.3 \%$ in subjects with no-AKI, in opposition to a $6.7 \%$ in subjects with AKI (RR: 0.816; CI 95\%: 0.21-3.07; $\mathrm{P}=.760$ ) (Table 2). The Kaplan-Meier curves (Figure 2) showed a greater mortality in subjects with AKI on comparing no-AKIN $(\mathrm{P}<.001)$. Cox regression analysis showed statistical significance in the presence of AKI (HR 2.808; CI 95\%: 1.49-5.29; $\mathrm{P}=.001$ ), mean blood pressure (HR 0.969; CI 95\%: 0.926-0.994; $\mathrm{P}=.015$ ) and age (HR 1.039; CI 95\%: 1.007-1.071; P=.015) (Table 4).

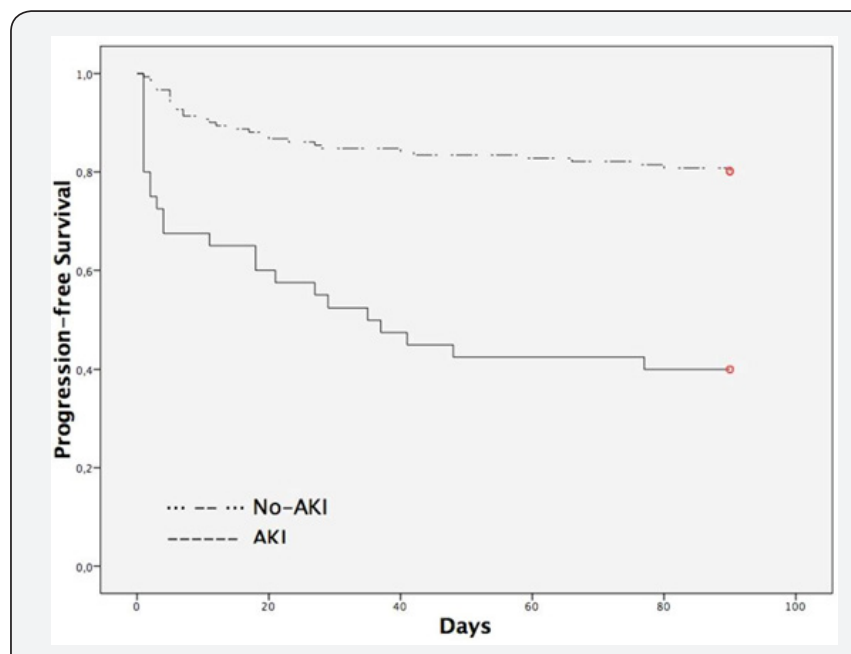

Figure 2:

${ }^{*} \mathrm{P}<.001$. AKI: Acute Kidney Injury.

Table 4: Variables associated with 90 -days mortality by Cox regression analysis*.

\begin{tabular}{|c|c|c|c|c|}
\hline Variable & $\boldsymbol{\beta}$ & HR & $\mathbf{9 5 \% ~ C I ~}$ & p-value \\
\hline Age (years) & 0,038 & 1,039 & $1,007-1,071$ & 0,015 \\
\hline Patients with AKI & 1,034 & 2,808 & $1,497-5,291$ & 0,001 \\
\hline $\begin{array}{c}\text { Mean Blood Pressure } \\
\text { (mm Hg) }\end{array}$ & $-0,016$ & 0,969 & $0,926-0,994$ & 0,044 \\
\hline
\end{tabular}

*HR: Hazard Ratio.

$\mathrm{Cl}$ : Confidence interval.

\section{AKI: Acute Kidney Injury.}

\section{Discussion}

This is the first prospective study to evaluate the association between worsening in renal function and the mortality of subjects with severe ARF. The severity of both hypoxemic and hypercapnic ARF is related to the need for NIV. The results of the present study indicate a lower survival among subjects with worsening in renal function compared to basal values and the greater the renal failure the worse the survival. The strength of our study lays in the use of the initial serum creatinine value compared with a reasonable recent basal determination. Therefore, the prognostic value of renal function may be determined at the time of initiating NIV. In the present study we demonstrate that the presence of renal failure triples the probability of death. The importance of this study is that it suggests that AKI has a previously unappreciated relationship among the prognostic factors of subjects receiving NIV.

The classical study on prognostic factors by Confalonieri et al. [8] did not include either the presence of renal failure or measurements of renal function such as serum creatinine or urea. Indeed, serum bicarbonate values reflecting acid-base equilibrium are often not included [1,3,7-9]. This study even proposed a prognostic scale including the APACHE. Thus, a greater mortality is observed with values $\geq 29$ in the APACHE scale. In our trial, we have used the SOFA scale in order to predict the mortality. As it was expected, taking into account the reference literature, the mortality in subjects with high SOFA was higher mortality. However, when the multivariate analysis was carried out, the SOFA scale disappeared from the model because of the presence of AKI. As the APACHE, SAPS II and SOFA scales included the kidney function, it is likely that the worsening of the kidney function is an independent variable and very important in the mortality of subjects undergoing a NIV. A recent study by Pacilli et al. [3] reported $18.2 \%$ of moderate or severe renal failure in COPD subjects with hypercapnic ARF requiring NIV. This value is closer to that observed in our study in which the mean age of the subjects was also over 75 years.

However, although this study determined the success of NIV as discharge to a hospital ward from the respiratory ICU, they observed $28.6 \%$ vs. $14.9 \%$ of moderate or severe renal failure in subjects with technique failure. Although only almost statistically significant $(\mathrm{P}=.069)$, this result is similar to our results. The present study has the advantage of being prospective and having renal function as its principal objective. However, on analyzing the relationship between serum creatinine levels and mortality, again no differences were found, except for the in-hospital mortality where it could be found. This corroborates the argument that acute worsening in renal function is a fundamental factor for prognosis, being stronger than punctual measurement of renal function [14,18-19]. Therefore, in cases in which basal serum creatinine levels are not available, the use of serum creatinine can help the emergency physician to come to a decision. With respect to IMV the study by Nim et al. [19] reported that subjects with an increase in serum creatinine levels above $0.3 \mathrm{mg} / \mathrm{dl}$ within 24 hours and basal serum creatinine levels $\leq 1.4 \mathrm{mg} / \mathrm{dl}$ carried an in-hospital mortality of $56 \%$. The mortality in the group without an increase in basal serum creatinine was $36 \%$. Although the mortality rates in our study were not as high, our results support the results of this group 
since the mortality rate tripled in our study (30\% in the group with AKI and $11 \%$ in subjects without). The "low" mortality rate in our study is probably due to its having been performed in subjects with NIV, because the IMV behaves as independent factor of mortality in subjects with AKI [10]. This proves that the kidney function is a determinant factor in the prognosis made to subjects with ARF undergoing mechanical ventilation, both invasive and non invasive. Our trial wasn't designed to monitorizated the creatinin's levels after the initiation of NIV. Hence, the weight of the NIV as factor in the development of AKI is unknown nowadays. Therefore, more researches are needed. As mentioned previously, bicarbonate levels are often not included as a prognostic factor of NIV, but have a low predictive power [5].

However, studies describing a relationship have observed that high levels of bicarbonate (greater than $25 \mathrm{mmol} / \mathrm{L}$ ) carry a better prognosis $[3,4]$. We did not find a relationship between serum bicarbonate levels and mortality but we did observe lower levels in the presence of AKI. Traditionally, the $\mathrm{pH}$ has been given a very important factor to prognosis. Therefore, the lower the $\mathrm{pH}$, the worst the prognosis [6,7]. However, in our trial as well as in others [1], a relationship between and the prognosis was not observed. Similary, the same can be said for the pCO2. The classical hypothesis was that a higher level of pCO2 led to a lower $\mathrm{pH}$ and, therefore, a worse prognosis [7-8]. Moreover, our study as well don't prove this. Hence, there has to be another important factor that influenciates in the $\mathrm{pH}$ as well as in the prognosis. One explanation for the behave of the $\mathrm{pH}, \mathrm{pCO} 2$ and HCO3-, may be that subjects with mainly hypercapnic ARF require an increase in serum bicarbonate to compensate for the associated acidosis. If these subjects presented AKI they would not be able to increase bicarbonate levels and consequently their $\mathrm{pH}$ levels would be lower. Since AKI carries a higher mortality this would explain the association between the higher mortality, low $\mathrm{pH}$ levels and not high serum bicarbonate levels as described in previous studies [1-6].

The main limitation of the present study is the different use of the AKIN criteria. These criteria are based on changes in serum creatinine or diuresis once the patient has been admitted. However, we evaluated the changes between serum creatinine levels at admission and within the previous 3 months. These "recent" serum creatinine levels were chosen with the aim of detecting subjects with AKI earlier since strict use of the AKIN criteria leads to a delay during which these time-dependent pathologies may worsen. The second limitation of the study is the cutoff of 3 months for creatinine levels. This time point was selected with the aim of having relatively "recent" values to carry out the study. Notwithstanding, in almost $20 \%$ of the cases the previous serum creatinine levels were not available. The last limitation is the relative small number of subjects with AKI. This fact is made worse in subjects classificated as AKIN 2 and AKIN 3. Therefore, it is fundamental for the research of more studies that valorate the behave in the changes in the kidney function in subjects undergoing NIV. Strangely enough subjects with AKI do not possess a higher possibility of being in ICU admission. Once more, the kidney function is the forgotten one in subjects undergoing a NIV. This study is just the first step. It is clear that the way we deal with AKI subjects has to change. The best path is yet to be discovered. In conclusion, the presence of AKI measured according to the AKIN criteria is an independent factor of mortality in subjects with ARF requiring NIV in the ED.

\section{References}

1. Antro C, Merico F, Urbino R, Gai V (2005) Non-invasive ventilation as a first-line treatment for acute respiratory failure: "real life" experience in the emergency department. Emerg Med J EMJ 22(11): 772-777.

2. Nava S, Hill N (2009) Non-invasive ventilation in acute respiratory failure. Lancet Lond Engl 374(9685): 250-259.

3. Pacilli AMG, Valentini I, Carbonara P, Marchetti A, Nava S (2014) Determinants of noninvasive ventilation outcomes during an episode of acute hypercapnic respiratory failure in chronic obstructive pulmonary disease: the effects of 15 comorbidities and causes of respiratory failure. BioMed Res Int Volume 2014 (2014): 9.

4. Lemyze M, Taufour P, Duhamel A, Temime J, Nigeon O, et al. (2014) Determinants of noninvasive ventilation success or failure in morbidly obese subjects in acute respiratory failure. PloS One 9(5): e97563.

5. Merlani PG, Pasquina P, Granier JM, Treggiari M, Rutschmann O, et al. (2005) Factors associated with failure of noninvasive positive pressure ventilation in the emergency department. Acad Emerg Med 12(12): 1206-1215.

6. Phua J, Kong K, Lee KH, Shen L, Lim TK (2005) Noninvasive ventilation in hypercapnic acute respiratory failure due to chronic obstructive pulmonary disease vs. other conditions: effectiveness and predictors of failure. Intensive Care Med 31(4): 533-539.

7. Confalonieri M, Garuti G, Cattaruzza MS, Osborn JF, Antonelli M, et al. (2005) A chart of failure risk for noninvasive ventilation in subjects with COPD exacerbation. Eur Respir J 25(2): 348-355.

8. Kuiper JW, Groeneveld ABJ, Slutsky AS, Plötz FB (2005) Mechanical ventilation and acute renal failure. Crit Care Med 33(6): 1408-1415.

9. Koyner JL, Murray PT (2010) Mechanical ventilation and the kidney. Blood Purif 29(1): 52-68.

10. Van den Akker JPC, Egal M, Groeneveld ABJ (2013) Invasive mechanical ventilation as a risk factor for acute kidney injury in the critically ill: a systematic review and meta-analysis. Crit Care Lond Engl 17(3): R98.

11. Bellomo R, Ronco C, Kellum JA, Mehta RL, Palevsky P (2004) Acute Dialysis Quality Initiative workgroup. Acute renal failure - definition, outcome measures, animal models, fluid therapy and information technology needs: the Second International Consensus Conference of the Acute Dialysis Quality Initiative (ADQI) Group. Crit Care 8(4): R204-R212.

12. Mehta RL, Kellum JA, Shah SV, Molitoris BA, Ronco C, et al. (2007) Acute Kidney Injury Network: report of an initiative to improve outcomes in acute kidney injury. Crit Care 11(2): R31.

13. Barrantes F, Tian J, Vazquez R, Amoateng Adjepong Y, Manthous CA (2008) Acute kidney injury criteria predict outcomes of critically ill subjects. Crit Care Med 36(5): 1397-1403.

14. Lombardi R, Nin N, Lorente JA, Frutos Vivar F, Ferguson ND, et al. (2011) An Assessment of the Acute Kidney Injury Network CreatinineBased Criteria in Subjects Submitted to Mechanical Ventilation. Clin J Am Soc Nephrol 6(7): 1547-1555.

15. Fernández Vivas M, González Díaz G, Caturla Such J, Delgado Vílchez FJ, Serrano Simón JM, , et al. (2009) [Use of non-invasive ventilation 
in acute respiratory failure. Multicenter study in intensive care units]. Med Intensiva 33(4): 153-160.

16. Appendini L, Patessio A, Zanaboni S, Carone M, Gukov B, et al. (1994) Physiologic effects of positive end-expiratory pressure and mask pressure support during exacerbations of chronic obstructive pulmonary disease. Am J Respir Crit Care Med 149(5): 1069-1076.

17. Abosaif NY, Tolba YA, Heap M, Russell J, El Nahas AM (2005) The outcome of acute renal failure in the intensive care unit according to
RIFLE: model application, sensitivity, and predictability. Am J Kidney Dis 46(6): 1038-1048.

18. Waikar SS, Bonventre JV (2009) Creatinine kinetics and the definition of acute kidney injury. J Am Soc Nephrol 20: 672-679.

19. Nin N, Lombardi R, Frutos Vivar F, Esteban A, Lorente JA, et al. (2010) Early and small changes in serum creatinine concentrations are associated with mortality in mechanically ventilated subjects. Shock Augusta Ga 34(2)109-116.
Your next submission with Juniper Publishers

$$
\text { will reach you the below assets }
$$

- Quality Editorial service

- Swift Peer Review

- Reprints availability

- E-prints Service

- Manuscript Podcast for convenient understanding

- Global attainment for your research

- Manuscript accessibility in different formats

( Pdf, E-pub, Full Text, Audio)

- Unceasing customer service

Track the below URL for one-step submission https://juniperpublishers.com/online-submission.php 